\title{
POWER QUALITY ISSUES IN A HYBRID POWER SYSTEM
}

\author{
E. Muljadi * \\ H.E. McKenna
}

National Wind Technology Center

National Renewable Energy Laboratory

1617 Cole Boulevard, Golden, CO 80401

(303) 384-6904 eduard_muljadi@nrel.gov $\quad$ http://www.nrel.gov

\begin{abstract}
We analyzed a power system network, which consisted of two types of power generation: wind turbine generation and diesel generation. The power quality and the interaction of diesel generation, the wind turbine, and the local load were the subjects of investigation.
\end{abstract}

From an energy-production point of view, it is desirable to have as much wind energy production as possible in order to save fuel consumption of the diesel engines and to reduce the level of pollution. From the customer point of view, it is desirable to have good power quality at the receiving end.

The purpose of this paper is to show the impact of wind power plant in the entire system. Also, we discuss how the startup of the wind turbine and the transient condition during load changes affects the voltage and frequency in the system.

Key words: wind turbine, diesel generator, hybrid power system, power quality, renewable energy

\section{INTRODUCTION}

Since ancient times, wind turbine technology has been used to improve the quality of life for many people. People have used wind turbines to pump water, mill grain, and many other uses $[1,2,3,4]$.

In today's world, wind turbines are used for similar purposes (i.e., water or oil pumping, battery charging, or utility generation). One important aspect of wind turbine applications, especially in an industrial environment, is that wind turbines generate electricity without creating pollution. In addition, the generation of electricity using wind turbines is well suited for isolated places with no connections to the outside grid $[2,3,4]$.

This paper analyzes a hybrid power system consisting of wind turbines, diesel generators, a local load. The result and the conclusion of the analysis are applicable for any similar hybrid power systems.

\section{SYSTEM CONFIGURATION}

A physical diagram of the system that was analyzed is shown in Figure 1. The wind turbine is operated with an induction generator with a capacity from $40 \mathrm{~kW}$ to 225 $\mathrm{kW}$. In low wind speeds, the generator is operated at a lower generator speed $(900 \mathrm{rpm}$, rated at $40 \mathrm{~kW})$ and at high wind speeds the generator speed is 1,200 rpm with rated capacity of $225 \mathrm{~kW}$. Only a fixed-speed wind turbine is discussed; variable-speed wind turbine generation [5] will not be covered.

The diesel engines have different rated capacities. They are operated in parallel to supply the load. The local loads are mostly residential and light loads. Other loads include water pumps, compressors, and other heavy equipment. The transient condition of a heavy load is represented by an $80 \mathrm{~kW}$ water-pump.

The system has two types of generation: the diesel generator and the wind turbine generator (Figure 1). The diesel generator provides smooth generation, whereas

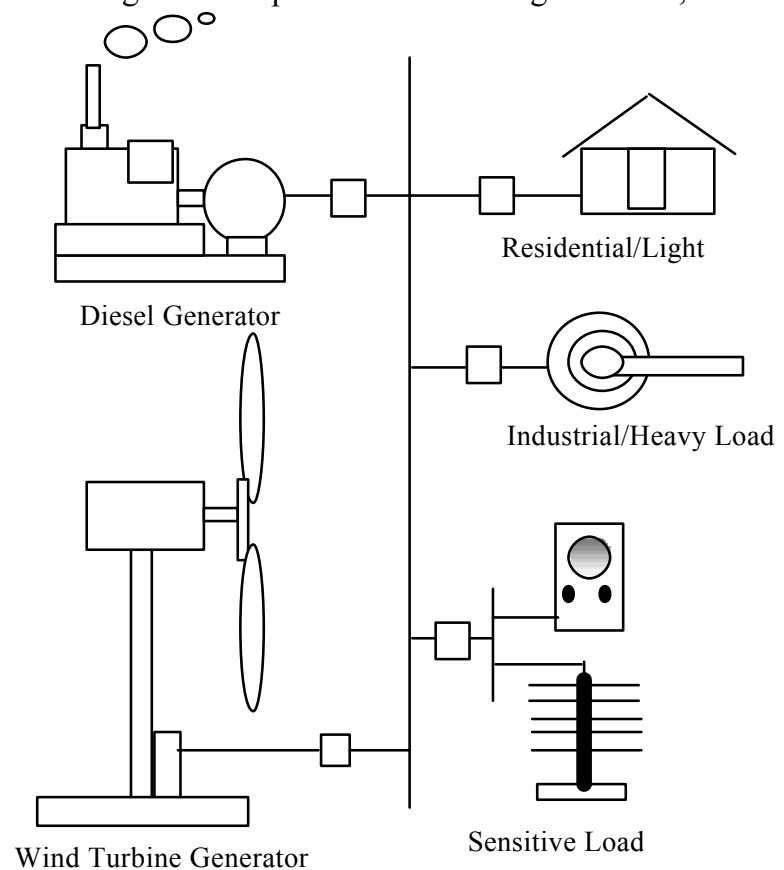

Figure 1. Physical diagram of the analyzed power system 
the output power of a wind turbine generation depends on the wind velocity. The wind velocity is reflected in the power generation. For example, if the wind changes very smoothly, the output power of the wind turbine will also change very smoothly. On the other hand, wind turbulence causes the output power to fluctuate

The load can be divided into three different types of loads. The first is the residential type of load for lighting, heating, or powering small appliances. The nature of this load is very tolerant of disturbance (immune to lowquality power, such as fluctuating voltage and frequency). The second type of load is the industrial or heavy load, such as compressors, water pumps, and intermittent large loads. This type of load, although insensitive to power quality, may cause voltage and frequency fluctuations on a weak grid. Another type of load is the sensitive load. This load may consist of radar, medical equipment, transceivers, or receivers.

\section{COMPONENTS OF POWER SYSTEM}

The system under discussion in this paper consists of three major subsystems: diesel generator, wind turbine generator, heavy (industrial) loads. In the power system network, the balance of active power and reactive power must be maintained. Thus, the diesel genset must be able to keep the power balanced when the wind turbine or local load varies. While important, details of the dynamic model for electric machines will not be covered here. Many good textbooks are available on this subject $[6,7]$.

\section{A. Diesel Generator}

From an electrical system point of view, a diesel generator can be represented as a prime mover and generator. Ideally, the prime mover has the capability to supply any power demand up to rated power at constant frequency, and the synchronous generator connected to it must be able to keep the voltage constant at any load condition.

The block diagram of the diesel generator is illustrated in Figure 2. The diesel engine keeps the frequency constant by maintaining the rotor speed constant via its governor.

The synchronous generator must control its output voltage by controlling the excitation current. Thus, the diesel generating system as a unit must be able to control its frequency and its output voltage. The ability of the diesel generator to respond to frequency changes is affected by the inertia of the diesel genset, the sensitivity of the governor, and the power capability of the diesel engine. The ability of the synchronous generator to control its voltage is affected by the field winding time constant, the availability of the DC power to supply the field winding, and the response of voltage control regulation.

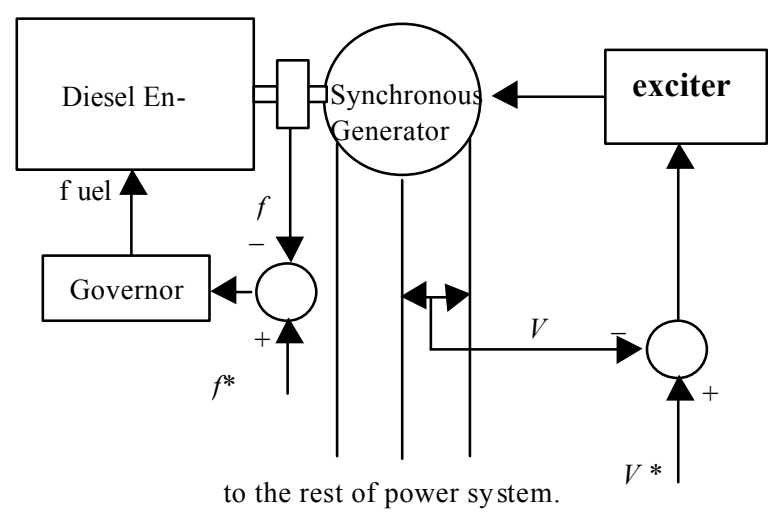

Figure 2. Diesel Generator Control Block Diagram

The diesel engine must be capable of following the variation of loads and wind generation. The size of frequency variation indicates how well the diesel and its governor maintains the balance of active power in the system. And the size of voltage variation indicates how well the genset and its voltage regulator maintains the balance of reactive power through its excitation. Under transient conditions, the frequency and the voltage will not be absolutely constant due to constantly changing wind speeds and load variations.

\section{B. Wind Turbine Generator:}

The power and the torque generated by the wind turbine are as follows:

$$
\begin{aligned}
& P=0.5 \rho A C_{p} V^{3} \\
& T=\frac{P}{\omega_{s}}
\end{aligned}
$$

where:

$\rho=$ density of air

$A=$ swept area of the blade

$C_{p}=$ performance coefficient

$V=$ wind speed.

$T=$ mechanical torque (at low speed shaft)

$P=$ output power of the turbine

$\omega_{\mathrm{S}}=$ rotor speed of the wind turbine - low speed shaft.

A typical $C_{p}$ curve is shown in Figure 3. This characteristic defines $C_{p}$ as a function of the tip-speed ratio

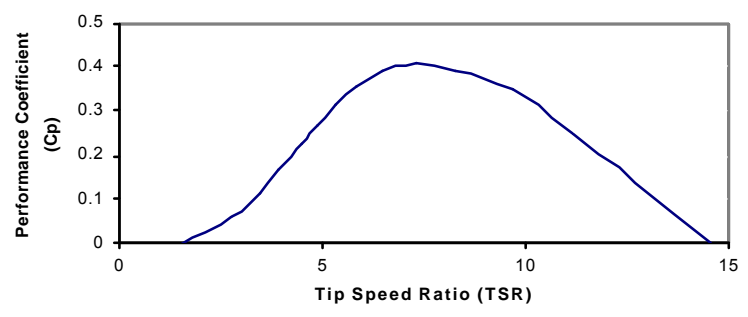

Figure 3. A typical $C_{p}$ versus tip-speed ratio curve 
(TSR) given by the equation 3 :

$$
T S R=\frac{\omega_{s} R}{V}
$$

where

$R$ is the radius of the wind turbine rotor.

Since this is a fixed-pitch turbine, the wind turbine must rely on the blade-stall condition to limit the output power when the winds are at high speed. During a stall condition, the wind turbine operates at a very low efficiency $\left(C_{p}\right.$ is very low). The tip speed ratio for a fixed-speed wind turbine varies with wind speed (Figure 4). Note that although the rotor speed of an induction generator varies with wind speed, the speed range is within one- to twopercent slip. On the other hand, the wind speed variation may range from $5 \mathrm{~m} / \mathrm{s}$ to $25 \mathrm{~m} / \mathrm{s}$; thus, from the wind turbine point of view the induction generator operates at relatively "fixed speed" compared to the range of wind speed variation. At high wind speeds, the tip speed ratio is expected to be low (to the left side of $C_{p \max }$ in Fig. 3) as the wind speed increases at relatively "fixed" rotor rpm. The term "fixed speed" is commonly used to describe a wind turbine mechanically coupled to a constantfrequency induction machine. In reality, the rotor speed

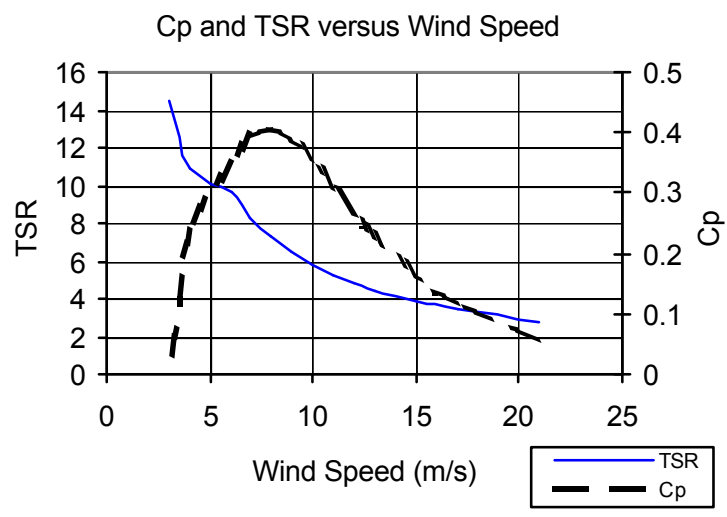

Figure 4. $C_{p}$ and $T S R$ as a function of wind speed for a fixed-speed turbine.

Power and $\mathrm{dP} / \mathrm{dV}$ versus Wind Speed

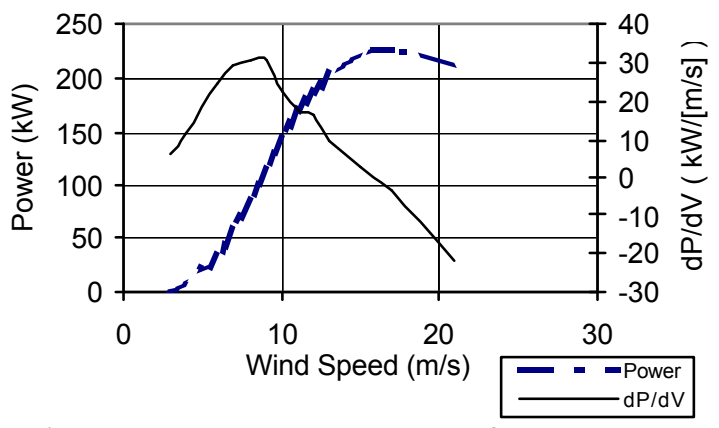

Figure 5: Power curve and rate of power change of a typical wind turbine. of wind turbine varies with the slip $(0-2 \%)$ as the wind speed varies.

As shown in Figure 4, the performance coefficient $\left(C_{p}\right)$, which represents the efficiency of the wind turbine, varies as the wind speed increases. As the wind speed increases, the TSR decreases and the $C_{p}$ increases until it reaches the maximum $C_{p}$ at $T S R=7.8$ (which corresponds to about $8 \mathrm{~m} / \mathrm{s}$ for this wind turbine). As the wind speed continues to increase, the performance coefficient $C_{p}$ declines. This process makes the wind turbine self-regulate its output power by operating at lower efficiency at high wind speed.

A typical power curve and the rate of power change of a wind turbine are presented in Figure 5. The rate of change of the output power versus wind speed occurs at maximum $C_{p}$, which is about $8 \mathrm{~m} / \mathrm{s}$. In the high wind speed region, the rate of change is diminished when the wind turbine goes into stall mode (lower $C_{p}$ ). This is good news for the power system environment. Thus, wind turbulence reflected in the power system network weakens as the wind turbine operates in high wind speeds (stall region). Power fluctuation is not linearly proportional to the cube of wind speed, especially in the high wind speed region.

The inertia of the turbine rotor (including the blades), together with the shape of the $C_{p}-T S R$ curve, behaves like a low-pass filter that damps out the high-frequency power fluctuation in the power network. This low-pass filter screens out the wind-speed fluctuation in the highwind-speed region so that the resulting output power is smoother than the wind-speed fluctuation, especially in high wind speeds.

\section{Induction Machines}

Most electric machines used as the prime mover in industry are induction motors. Two applications of induction machines in the power system network fall within the scope of this study. One application is as generator on a wind turbine and the other is as a motor driving large pumps and compressors. By its nature, an induction machine is an inductive load. Either as a motor or generator, this machine absorbs reactive power. The reactive power absorbed by the induction machine comes from the line to which it is connected. In a hybrid power, the reactive

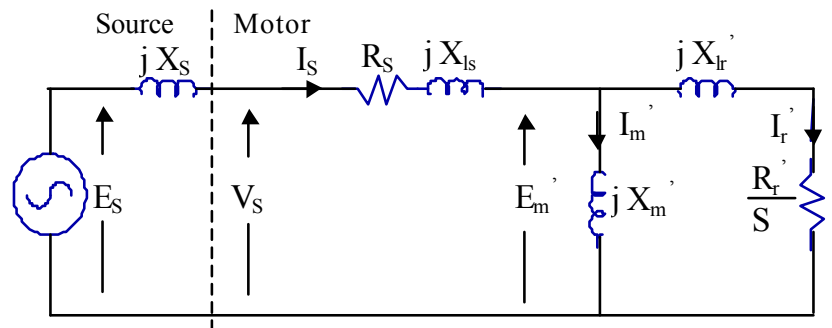

Figure 6. Equivalent circuit of an induction machine connected to power system. 


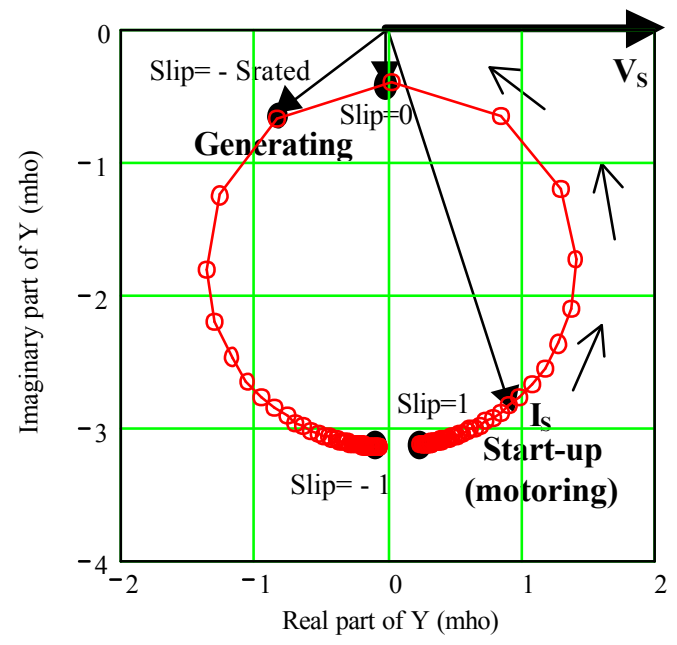

Figure 7: Current locus of an induction machine from the start-up as a motor to operation as genera-

power comes from the synchronous generator of the diesel genset.

In a wind turbine generator, a fixed capacitor is usually installed to supply some of the reactive power needed by the induction generator. The equivalent circuit of an induction machine connected to a power system is given in Figure 6 . The power system is represented by the infinite bus $E_{\mathrm{s}}$ and reactance $\mathrm{X}_{\mathrm{s}}$ which represents the line impedance.

Figure 7 shows the admittance of a typical induction machine as the operating slip varies from slip $=1$ (motoring) to slip $=-1$ (generating). The admittance diagram illustrates a variable load connected to a voltage source. It illustrates the current path as the operating condition changes. If the induction machine is connected to an infinite bus, the admittance diagram shows how the induction machine current (the magnitude and phase angle) varies as the operation changes from start-up as a motor to operation as a generator. A large inductive current is drawn during start-up ( $\operatorname{lip}=1$ ), and it shrinks as the slip moves closer to the synchronous speed where the current is minimum. As the induction machine enters the generating region ( $\operatorname{slip}<0$ ), the current increases. In the entire region of operation (both as a motor and as a generator), the current always operates in the inductive (lagging) mode. The stator current changes in magnitude and phase angle (power factor) from start-up to generating rated power

\section{Voltage variation due to load changes.}

Between the load and an infinite bus in a power network, impedance represents the line impedance, the transformer impedance, and other elements. Although an infinite bus can maintain its voltage, the voltage at the terminal of the load varies due to variation in the drop in volt-
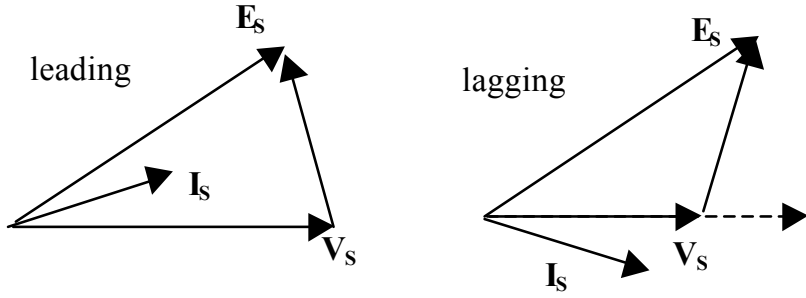

Figure 8: Terminal voltage changes as the phase angle of the load current is converted from leading to lagging for the same current amplitude and power factor.

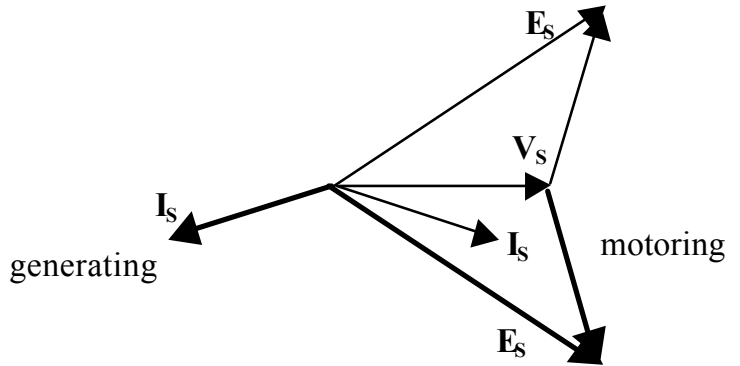

Figure 9: Terminal voltage changes as the load changes from motoring to generating.

age across the line impedance. The voltage drop across the impedance depends on the size of the current and the power factor of the load.

The terminal voltage varies $\left(\mathrm{V}_{\mathrm{S}}\right)$ as the load current is changed from leading to lagging for the same current magnitude and the same power factor (Figure 8). The terminal voltage $\left(\mathrm{V}_{\mathrm{S}}\right)$ of an induction machine drops (with respect to an infinite bus $\mathrm{E}_{\mathrm{S}}$ ) as the induction machine is operated at the same power factor (both lagging) and the same current magnitude (Figure 9).

In Fig. 10, per-phase terminal voltage $\mathrm{V}_{\mathrm{S}}$ (line-toneutral) variation is shown as the induction machine is

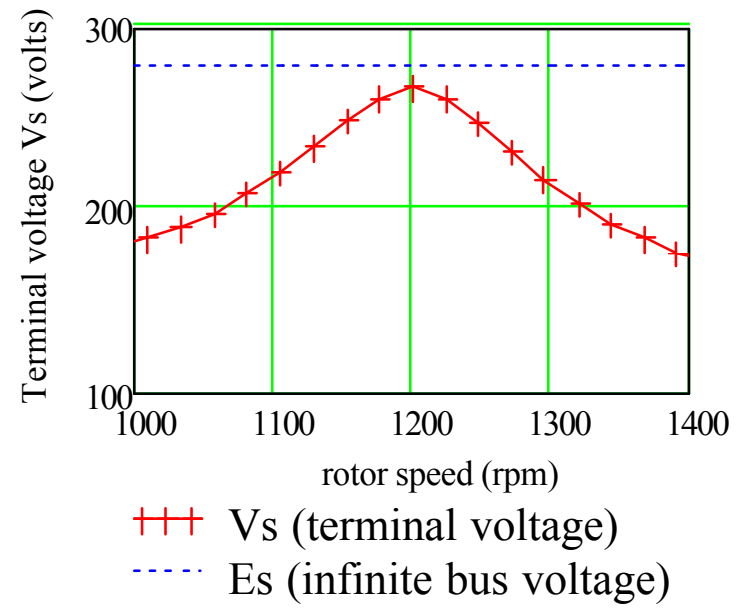

Figure 10: Per phase terminal voltage variation as the generator speed varies (synchronous speed is 1,200 rpm). 
operated from start-up as a motor and then as it is operated as a generator. During start-up, voltage drops significantly at the terminal voltage of the induction machine. The voltage drop across line impedance is caused by the current surge during start-up. In addition, the phase angle of the stator current is very large and lagging (Figure 7). The combination of poor power factor, lagging, and large current surge creates a voltage dip at the terminal of the induction machine during start-up. Thus, a short duration of start-up is preferable to a prolonged one. One way of reducing the voltage drop during startup is to reduce the starting current. This is accomplished by using variable-frequency drives (as in variable-speed wind turbine) or a soft-start device. Although the duration of start-up is prolonged when using the soft-start, the voltage drop across the line impedance is reduced significantly. The voltage dip occurs only at the time of very high slip (i.e., during start-up). In the operating slip region $($ slip $= \pm 2-3 \%$ ), the voltage drop is very small.

\section{DYNAMIC ANALYSIS}

In this section, the power system we studied is simulated using a package program RPMSim, developed at the National Renewable Energy Laboratory [4]. The case studies are intended to look at different aspects of major power systems components in the power network. The major component investigated is the diesel power. A diesel generator must respond properly to changes in the power balance in the power network. The power balance in the power network is maintained by the diesel control.

\section{Case Study I: Wind Turbine Start-up}

During start-up, the in-rush current entering the induction machine operating as a generator may cause a voltage dip on the power system network. Many wind turbine designers let the wind turbine self-start by using wind energy to bring the generator rpm up to speed and then connecting the generator when it is near its synchronous speed. Thus, the motoring interval is very short.

\section{Single-speed and two-speed wind turbines:}

A single-speed wind turbine is equipped with only one generator. One advantage is that many off-the-shelf, single-speed induction machines are available from many manufacturers. A single-shaft input-output gearbox is needed to transfer the aerodynamic power from wind to the generator. Two-speed wind turbines can be implemented by using two induction machines with different speed ratings or by using one induction machine with two different windings with a different number set of poles wound on the same stator frame. When two induction machines are used, the wind turbine needs to use a gearbox with a single-shaft input connected to the lowspeed shaft and two output shafts connected to the two generators. On the other hand, with a single-induction machine with two sets of windings, the gearbox needs to be connected to a single shaft only. The dual winding must be a custom-wound induction generator. From an energy point of view, the two-speed wind turbine can yield more energy than a single-speed wind turbine because the wind turbine can be operated at low rpm when the wind is low and it can be operated in higher rpm when the wind speed is high. The simulation is started with zero initial output voltage and zero initial speed of the diesel generator. Thus, the observation is started after $t$ $=1.5 \mathrm{~s}$ when both the voltage and the frequency reach their rated values. The rated output of the diesel genset is set to $750 \mathrm{~kW}$ and the line-to-line voltage reference is 480 volt.

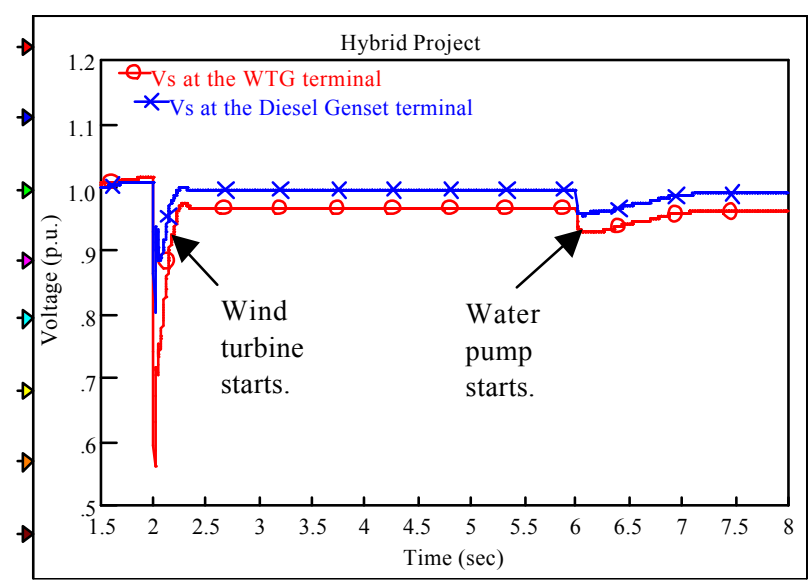

Figure 11: Per phase voltage variations at the terminal of the wind turbine and at the terminal of the diesel generator.

Figure 11 shows the voltage variation at the terminal of the wind turbine and at the terminal of the synchronous generator as the wind turbine is started and load is applied. The wind turbine is self-started (i.e., the turbine starts as the wind speed increases). The wind turbine is connected to the power network as the generator speed reaches $1,050 \mathrm{rpm}$ (about $83 \%$ of synchronous speed) at $t$ $=2 \mathrm{~s}$. The start-up electrical transient is over within less than $0.5 \mathrm{~s}$ due to self-start capability of the wind turbine. The voltage dips at the diesel genset terminal drop about $13 \%$ before the exciter of the synchronous generator recovers voltage to normal voltage. As expected, when starting (motoring) the wind turbine generator, the voltage at the terminal of the wind turbine generator $\left(\mathrm{V}_{\mathrm{S}}\right)$ is lower than the voltage at the terminal of the synchronous generator due to voltage drop across the line impedance between the diesel genset and the wind turbine.

Figure 12 shows the frequency variation as the wind turbine is started at $t=2 \mathrm{~s}$. The frequency dips about 5 


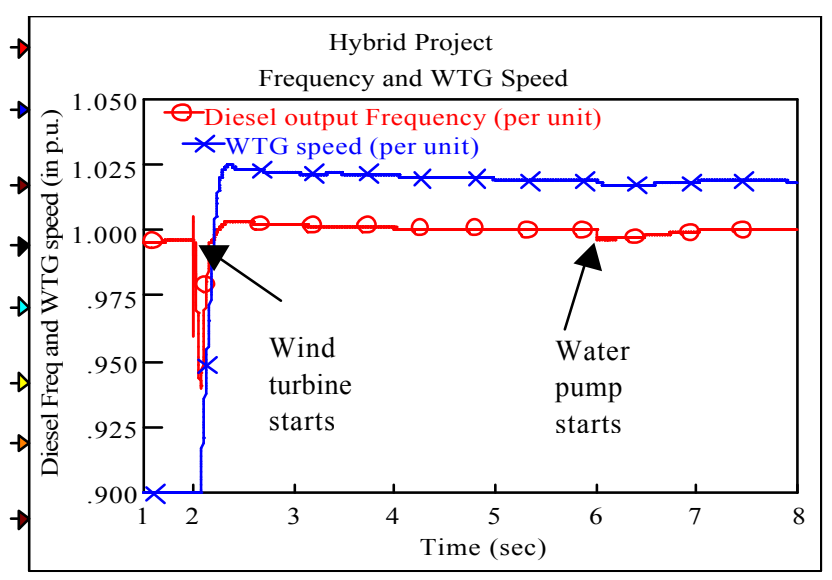

Figure 12: The speed of wind turbine and the output frequency of the diesel generator.

percent before it recovers to the normal frequency. Also shown in Figure 12 is the trace of wind turbine speed. Once the wind turbine speed passes the synchronous speed (above 1.0 per unit or p.u.), the induction generator starts generating. As seen on the chart, the rotor speed varies as the wind changes. The output frequency of the diesel genset also varies due to imperfections of the diesel governor in keeping the frequency constant.

A two-speed wind turbine that uses a smaller generator to start the wind turbine will show a less severe deviation in voltage and frequency. This is because the starting current of the smaller-sized generator is much smaller than the starting current for a large generator.

\section{Sequential start-up of wind turbines:}

Most wind farms have a number of turbines. Some turbines are installed in a straight line with distance between two turbines spaced at least three blade diameters with respect to one another. If the wind comes in a perpendicular direction to this line of turbines, the wind will reach the turbines at the same instant. Thus, all the turbines in the line may starts at the same time, creating an accumulation of surge current drawn from the power system. In this case, the voltage dip is amplified. On the other hand, if the turbine is not perpendicular to the line, there will be delay between the start-up of one turbine with respect to the next turbine. The voltage and frequency dips recover before the next turbine starts. A signal can be added to each individual turbine that tells the turbine to start up during the short period of time between the start-up of one turbine after another. With a sequential start-up, instantaneous start-up can be avoided and severe voltage dips can be avoided.

\section{Case Study II: Water Pump Start-up}

The prime mover of the water pump and compressor are the same. Both of them are driven by the induction mo- tor. The startup of a large induction motor can significantly affect the voltage dip and frequency dip on the power system.

Direct on-line start for a water pump and compressor have the same effect on the power system as the wind turbine start-up. The difference is that in a wind turbine, the wind helps the generator reach its synchronous speed faster, whereas in a water pump or compressor, the pump or compressors do not. In a two-speed wind turbine the smaller induction machine is used during startup, thus the voltage and frequency dip is not the same as if the larger induction machine is used during start-up.

In Figure 11 the voltage dips are due to the start-up of the water pump at $t=6 \mathrm{~s}$. The voltage reduction is much smaller than the one caused by wind turbine start-up (about $4.3 \%$ ). This is obvious because the size of the water pump is only $80 \mathrm{~kW}$ (35\% of the size of the wind turbine). The voltage at the terminal of the wind turbine is also affected by the voltage drop at the terminal of the synchronous generator. In Figure 12, the frequency variation during the start-up of the water pump (at $t=6 \mathrm{~s}$ ) is barely noticeable.

A wind turbine is started up when the generator speed is very close to the rated speed. Thus the transient time during the start-up of the wind turbine is shorter than the transient time during the start-up of the water pump.

The real power of the diesel, wind turbine, water pump, and the local load is shown in Figure 13, which also shows how the interaction among the generators and the loads takes place. The sign convention for real power and reactive power is that a positive sign means that a particular piece of equipment is producing real power or reactive power and a negative sign means that the equipment is absorbing real power or reactive power. Initially, the synchronous generator supplies a constant $400-\mathrm{kW}$ local load when, at $\mathrm{t}=2 \mathrm{~s}$, the wind turbine is turned on. The wind turbine is in the motoring mode

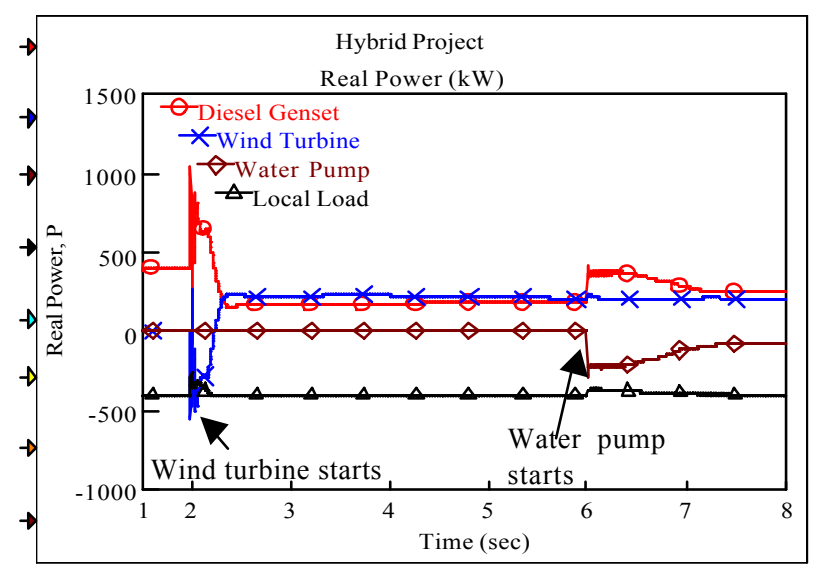

Figure 13: Real power of the diesel genset, wind turbine, water pump, and local load. 
while its speed is below synchronous speed; therefore, the power (and the reactive power) absorbed by the wind turbine must be supplied by the diesel genset. Once the wind turbine reaches synchronous speed, it starts producing power and contributes to power generation (supplying 400-kW local load). The diesel power generation drops from $400 \mathrm{~kW}$ to about $175 \mathrm{~kW}$ due to $225 \mathrm{~kW}$ of power contributed by the wind turbine. Also, the wind turbine generates relatively smooth power at high wind speed.

The water pump is started at $\mathrm{t}=6 \mathrm{~s}$. When it is started, the starting power required comes from the power system (diesel genset and wind turbine). Thus, the diesel genset must generate additional power to supply the start-up of the water pump. Once the transient period is over, the water pump absorbs a constant power of $80 \mathrm{~kW}$. The diesel genset and wind turbine share the total load of 480 $\mathrm{kW}$. The contribution from the wind turbine is relatively constant, and the power absorbed by the local load is also constant at $400 \mathrm{~kW}$.

\section{Case Study III: Diesel - Wind Turbine Interaction}

A diesel generator consists of a diesel engine and a synchronous generator. The diesel engine is responsible for controlling the frequency and keeping it constant through its governor and its diesel engine [as meant?]. The synchronous generator is responsible for controlling the voltage via its field winding and voltage controller.

\section{Undersized Diesel Engine:}

The ability of a diesel engine to change speed is its accelerating or decelerating power. The diesel accelerates when the diesel power is higher than the electrical output power of the generator (including losses). The diesel decelerates when the diesel power is lower than the electrical output power of the generator (including losses). An oversized diesel engine does not have problems in acceleration or deceleration, but an undersized diesel engine may create problems, for example during the startup of a wind turbine or large compressor.

Figure 14 illustrates a condition where the diesel is undersized with respect to the load. The genset frequency and the terminal voltage of the wind turbine generator are shown on the top graph, and the real power of the diesel, wind turbine, water pump, and local load are shown in the bottom graph. At the start-up, the wind turbine uses the smaller, $40-\mathrm{kW}$ generator to motor up the wind turbine and bring the induction machine up to speed. The wind is low, thus the wind turbine operates at low output power, and the local load is set to $200 \mathrm{~kW}$. The diesel engine has a rated power of $400 \mathrm{~kW}$. At $\mathrm{t}=2$ $\mathrm{s}$, the wind turbine is turned on. As we can see, the voltage dip and the frequency dip are not very large because the wind turbine is started up using a smaller generator.

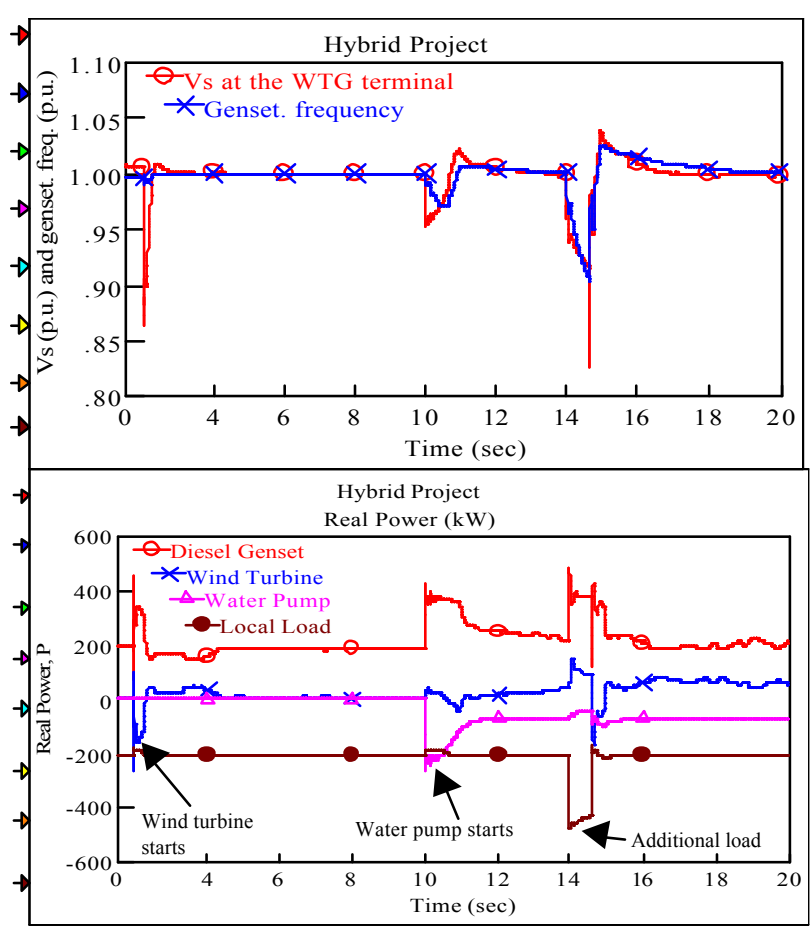

Figure 14. Voltage, frequency and power to illustrate an undersized diesel genset.

At $\mathrm{t}=10 \mathrm{~s}$, the $80-\mathrm{kW}$ water pump is started up. The start-up time for the water pump takes longer than the start-up time for the wind turbine because the wind turbine is started when rotor speed closed to the synchronous speed and it also gets some help from the wind. The voltage drop is not very significant, but the frequency of the diesel drops about 3\%. The diesel output power increases to cover the real power needed, whereas the contribution from the wind turbine is insignificant because the wind is low. The induction generator, for a short period of time, enters motoring region between $\mathrm{t}=$ $10.8 \mathrm{~s}$ and $\mathrm{t}=11.3 \mathrm{~s}$. After the condition is restored, at $\mathrm{t}=$ $14 \mathrm{~s}$, the additional local load $(300 \mathrm{~kW})$ is turned on, thus bringing the total load to $580 \mathrm{~kW}$. The diesel can only carry up to $400 \mathrm{~kW}$ and the contribution from the wind is very small (about $40 \mathrm{~kW}$ ). The voltage and frequency start decreasing. The voltage and frequency sensors detect the change. If the frequency drops below $95 \%$ and the voltage drops below $90 \%$ for an elapsed time of $0.5 \mathrm{~s}$, the controller will drop the additional load $(300 \mathrm{~kW})$ and keep the critical load $(200 \mathrm{~kW})$ to regain the voltage and frequency. After the load is shed at $\mathrm{t}=14.5 \mathrm{~s}$, the frequency and voltage eventually return to normal. When the frequency drops, there is a sudden jump of wind turbine power contribution due to a sudden increase of generating slip. Eventually, the genset frequency increases again for a short period of time and the induction generator enters into motoring condition (between $t=14.5 \mathrm{~s}$ and 
$t=15 \mathrm{~s})$. This condition is worsen if the mechanical time constant of the wind turbine rotor (including the blade) is higher than the diesel genset time constant. In other words, the changing of genset rotor speed is much faster than the changing of wind turbine rotor speed. The response to the load change is shown by how fast the governor corrects the frequency and how fast the field excitation control of the generator reacts to the voltage changes.

\section{Oversized Wind Turbine:}

An oversized wind turbine presents another problem to the diesel power plant. The diesel engine can only present a driving torque to the synchronous generator it is driving. It can only present a small braking torque when it is driven. The braking torque (if any) is due to the engine compression. The synchronous generator generates the power needed by the load in the power network. When the wind turbines operate, the power they generate offsets the diesel power. The balance of power is maintained by the diesel engine. Assuming a constant load, any increase in the wind power output means a reduction of the output diesel power. When the wind power output exceeds the power required by the load, the synchronous generator of the diesel genset becomes a synchronous motor that tends to accelerate the rotor speed of the diesel engine. Thus the excess energy from the wind power tries to drive the diesel engine. Because the diesel engine has only a small braking capability due to engine compression, the frequency control can be lost when the ex-

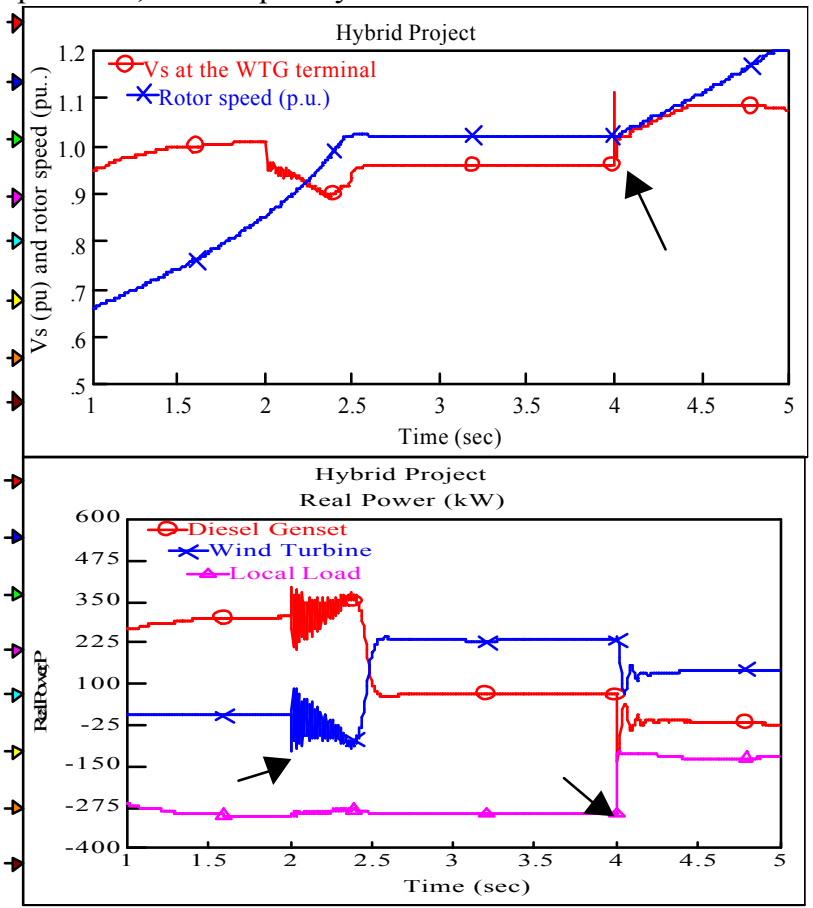

Figure 15. Voltage, rotor speed, and power of an ove $r$ size wind turbine. tra power generated by the wind turbine is sufficiently high.

In Figure 15, the diesel generator has rated power of $400 \mathrm{~kW}$, the local load is initially set to $280 \mathrm{~kW}$ at $\mathrm{t}=4 \mathrm{~s}$, and the local load is set to $100 \mathrm{~kW}$. When the diesel is started, there is only local load of $280 \mathrm{~kW}$. Then, the wind turbine is started at $\mathrm{t}=2 \mathrm{~s}$ with a $225-\mathrm{kW}$ induction machine. Although the diesel genset is rated at only 400 $\mathrm{kW}$ and the wind turbine is started with a $225-\mathrm{kW}$ induction machine, the effect of wind turbine start-up on the power system is very mild. This is mostly due to the fact that the induction machine current is limited by a soft start. As shown in Figure 13, the same wind turbine (225$\mathrm{kW}$ ) draws a starting power of $300 \mathrm{~kW}$. After the installation of the soft start (Figure 15), the power surge during start-up drops to about $100 \mathrm{~kW}$. Soft start is a device that limits starting current during start-up. It consists of a pair of back-to-back thyristors installed in series with each phase of the motor winding. Because the firing angle of the thyristor can be controlled, the size of the starting current can be adjusted by controlling the firing angle of the thyristors. Variable-frequency drive (VFD) is seldom used to start a wind turbine for economic reason. For a variable-speed wind turbine employing VFD (not the subject of this paper), the start-up capability is integrated to the system. Soft start is very useful to reduce the current surge during start-up of large induction machines, thus the voltage dip and frequency dip can be reduced.

During start-up, the resulting voltage dip at the wind turbine terminal is insignificant compared to direct online start-up (Figure 13). When the wind turbine is started, the voltage at the wind turbine drops to $90 \%$ In comparison, without a soft start, even with a larger diesel, the voltage at the wind turbine terminal drops more than $30 \%$ (Figure 11).

After the wind turbine enters generating mode (at about $\mathrm{t}=2.5 \mathrm{~s})$, the local load $(280 \mathrm{~kW})$ is shared between the diesel genset $(55 \mathrm{~kW})$ and the wind turbine $(225 \mathrm{~kW})$. The voltage and frequency are maintained constant. The diesel genset generates only a small percentage of its rated load (about 13\%). This is a significant contribution in fuel savings from the wind energy.

At $\mathrm{t}=4 \mathrm{~s}$, the local load is reduced from $280 \mathrm{~kW}$ to 100 $\mathrm{kW}$, while the wind speed stays the same. As a result, the wind turbine tries to supply $225 \mathrm{~kW}$, while the only load available is $100 \mathrm{~kW}$. As a result, the synchronous generator of the diesel genset turns into a motor (negative power), the governor loses its speed control, and frequency run-away occurs. This is an example of the wind turbine being oversized compared to the local load. In such a case, a dump load (water heater, water pump, 
battery charger, etc.) is usually deployed to keep the diesel genset generating, thus preventing it from motoring. Minimum power generation of the diesel genset is usually pre-set (for example, $15 \%-40 \%$ of the rated load). If the generated power of the diesel genset is less than the preset value, the dump load should be deployed. The dump load must be sized so that the diesel genset will always generate power above its minimum set point. The dump loads are normally non-critical loads used to store excess electrical energy into another form of energy, such as heat (water or space heater), electric charge (battery charging), or potential energy (water pump).

\section{CONCLUSIONS}

This paper starts with an overview of the components of the power system under investigation. The operating characteristics of the components are described as they relate to power quality in the power network. Steadystate predicted effects of wind power fluctuations on power system are presented.

The following factors contribute to voltage fluctuation:

- Voltage drop across the line impedance caused by large current surges.

- Current surges can be developed at the start-up of an induction machine operating from fixed frequency (large induction machines). In particular, they produce reactive current surges.

- Reduction to current surges can be accomplished as follows:

- For wind turbines with a dual-winding generator, use smaller-sized induction machines during start-up, connect the generator when the rpm starts rotating close to the synchronous speed of the generator. Or, use a soft start to control the stator current.

- For other large loads (water pumps or compressors), use a soft-start device to limit the current surges, use variable frequency drives if affordable, use sequential start-up when appropriate.

- Slow response of the exciter as the synchronous generator side reactive power mismatch.

- Uncoordinated capacitor switching.

The following factors contribute to frequency fluctuation:

- Large real power surges during start-up of the induction motor, wind power fluctuations, etc.

- Slow response of the governor control at the diesel side.

- Frequency dip when the diesel engine is loaded by a sudden large load or the diesel engine is under-rated with respect to the load.

- Frequency run-away when the wind turbine produces more power than needed. In this case, the diesel engine looses control of its rotor speed.
- Change in genset frequency that may affect the operation of the induction generator (i.e., during frequency fluctuation, the induction generator may enter the motoring region for a very short period of time).

Power fluctuation in the high wind speed region (what is the high wind speed region) is very mild compared to the wind fluctuation. Thus, the wind turbine acts as a low-pass filter to the wind-speed input.

Many technical solutions can be implemented to remedy the shortcomings presented in this paper. However, in any power generation, the economic implications of the solutions have to be considered very carefully.

\section{ACKNOWLEDGMENTS}

The authors also acknowledge strong support from the National Renewable Energy Laboratory and U.S. Department of Energy during the completion of this study. This project supported under contract number DE-AC3698GO10337.

\section{REFERENCES}

[1] E. Muljadi, L. Flowers, J. Green, M. Bergey, "Electrical Design of Wind-Electric Water Pumping," ASME Journal of Solar Energy Engineering, Nov. 1996, Vol. 118, pp. 246-252.

[2] J.T.G. Pierik, M. De Bonte. Quasi Steady State Simulation of Autonomous Wind Diesel Systems (Status Report), Report No. ECN-85-091, Netherlands Energy Research Foundation, Petten, May 1985.

[3] A.J. Tsitsovits and L.L. Freris, Dynamics of an Isolated Power System Supplied from Diesel and Wind, Proc. IEEE, 130, Part A, No. 9, pp. 587-595, 1983.

[4] J.T. Bialasiewicz, E. Muljadi, G. Nix, S. Drouilhet, "RPM-SIM simulator: A comparison of simulated versus recorded data, "Proceedings of WINDPOWER '98," Bakersfield, California, pp. 423-432, 1998.

[5] E. Muljadi, C.P. Butterfield, "Pitch-Controlled VariableSpeed Wind Turbine Generation," Transactions of the IEEE-Industry Applications Society, Jan/Feb 2001, Vol. 37, No. 1, pp. 240-246.

[6] P.C. Krause, and C.H. Thomas, Simulation of Symmetrical Induction Machinery, IEEE Trans Power Apparatus and Systems, Vol. 84, pp. 1038-1053.

[7] C.M. Ong, Dynamic Simulation of Electric Machinery Using Matlab/Simulink, Prentice Hall PTR, 1998. 